\title{
Impactos ambientais pelo uso e ocupação do solo em sub bacias hidrográficas de Campinas, São Paulo, Brasil
}

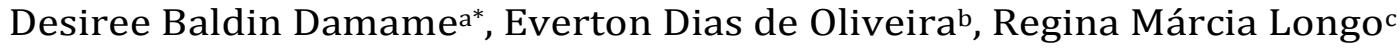 \\ a Programa de Pós-graduação em Planejamento de Sistemas Energéticos, Universidade Católica de Campinas, Cidade, CEP 13087- \\ 571, São Paulo, Brasil. *desireedamame@yahoo.com.br \\ b Programa de Pós-graduação em Engenharia de Produção, Universidade Metodista de Piracicaba, Santa Barbara, CEP 3451-900, \\ São Paulo, Brasil. \\ c Programa de Pós-graduação em Sistemas de Infraestrutura Urbana e em Sustentabilidade, Universidade Católica de Campinas, \\ Cidade, CEP 13083-970, São Paulo, Brasil.
}

Recebido: 31 julho 2018 / Aceito: 12 setembro 2018 / Publicado online: 2 janeiro 2019

\begin{abstract}
Resumo
As alterações promovidas por ações antrópicas em ecossistemas localizados em habitats urbanos vêm gerando a destruição de áreas com grande importância ambiental, como o que ocorre em pequenas bacias hidrográficas que vem sofrendo como consequência constantes episódios de enchentes. Essa pesquisa analisa e discute as consequências do uso e ocupação sobre os atributos de solo estudados permitindo dessa maneira ampliar a discussão sobre as relações entre a expansão urbana e a diminuição das áreas de vegetação e das áreas permeáveis em sub bacias hidrográficas urbanas. Assim, escolheu-se como área de estudo, as sub bacias Rio das Pedras e a do Baixo Anhumas, localizadas em Campinas, São Paulo. Foram analisados, em 2014, 37 pontos ao longo das sub bacias, a fim de caracteriza-los do ponto de vista ambiental, realizando também, coleta de amostras de solo (deformadas e indeformadas) para análises laboratoriais e realização de testes de resistência mecânica a penetração. Em geral, as sub bacias analisadas vêm sofrendo ao longo dos anos processos de fragilização de seus ecossistemas. Esse cenário de impactos antrópicos do solo em ambas as bacias, permite inferir que a ocupação urbana foi a responsável direta pelas alterações e perturbações ambientais sofridas na área.
\end{abstract}

Palavras-chave: Analises de solo, fragmentos, espaço urbana, urbanização.

\section{Environmental impacts of land use and occupation in subbasins of Campinas, São Paulo, Brazil}

\begin{abstract}
Changes promoted by anthropic actions in ecosystems located in urban habitats have generated the destruction of areas of great environmental importance, such as that occurring in small river basins that have suffered as a consequence of constant episodes of floods. This research discusses the consequences of land use and occupation on the soil attributes studied, thus allowing a broader discussion of the relationships between urban expansion and the reduction of vegetation areas and permeable areas in urban sub - basins. Thus, the subbasins Rio das Pedras and Baixo Anhumas, located in Campinas, São Paulo, were chosen as the study area. In the year 2014, 37 points were analyzed along the same lines, in order to characterize them from the environmental point of view, also collecting samples of deformed and undisturbed soil for laboratory analysis, besides the performance of tests of mechanical resistance to penetration, using a penetrometer. In general, the analyzed sub basins have been suffering over the years processes of fragilization of their ecosystems. This scenario of anthropic soil impacts in both basins allows us to infer that the urban occupation was directly responsible for the alterations and environmental disturbances suffered in the area.
\end{abstract}

Keywords: Soil analysis, fragments, urban space, urbanization.

\section{Introdução}

A Bacia hidrográfica é uma área de captação natural da água da chuva, definindo-se como micro bacia, aquela cuja área é tão pequena, que a sensibilidade às chuvas de alta intensidade e as diferenças nos tipos de uso do solo, não são suprimidas pelas características da rede de drenagem (Lima \& Zakia, 2000). Para a United Nations Food and Agriculture Organisation (FAO, 1995) degradação é definida como a perda temporária ou permanente da capacidade produtiva da área.

Com o aumento populacional, cresce a necessidade de desenvolvimento tecnológico, as demandas por alimentos, moradia, energia, recursos naturais, entre outros, e 
consequentemente, gera-se maior poluição decorrente destes. As grandes cidades, conforme se expandem, acabam prejudicando o solo, florestas, áreas úmidas e habitats de animais selvagens (Miller, 2007).

Nesse contexto, os remanescentes naturais foram reduzidos a pequenos fragmentos isolados em meio a atividades antrópicas, intensificando a ameaça sob a biodiversidade. (Tambosi, 2014). Tal fragmentação foi estudada por uma série de pesquisadores, dentre eles Fiszon et al. (2003), indicando que a fragmentação de habitats é, possivelmente, a mais profunda alteração causada pelo homem ao meio ambiente. O meio ambiente e os ecossistemas prestam inúmeros serviços a sociedade, tais como a produção de água, altera-los leva a graves consequências de longo e médio prazo (Oliveira \& Mattos, 2014).

Compreender a relação entre ocupação urbana e degradação ambiental é extremamente necessário para prevermos e evitarmos impactos futuros, tais como alagamentos, perda do potencial de geração de alimentos, poluição do ar e solo, impactos irreversíveis sob a fauna e flora. Conhecer as vulnerabilidades implica em entender a susceptibilidade e/ ou a resistência deste frente às pressões externas, a fim de identificar áreas com maior propensão a impactos (Moura, Grigio, \& Diodato, 2010).

Assim como em diversas bacias hidrográficas urbanizadas, a vulnerabilidade nas Sub Bacias do Rio das Pedras e Baixo Anhumas deve ser discutida, uma vez que a vegetação nativa foi quase em sua totalidade removida, ficando apenas pequenos fragmentos florestais naturais e alguns trechos de mata ciliar revegetada, as quais também sofreram pressões antrópicas.

Essa pesquisa analisa discute as consequências do uso e ocupação sobre os atributos de solo estudados permitindo dessa maneira ampliar a discussão sobre as relações entre a expansão urbana e a diminuição das áreas de vegetação e das áreas permeáveis em sub bacias hidrográficas urbanas.

\section{Material e Métodos}

\section{Caracterização da área de estudo}

A área de estudo localiza-se no município de Campinas, São Paulo e compreende as Sub Bacias do Rio das Pedras e Baixo Anhumas, ocupando cerca de $42 \mathrm{~km}^{2}$, sendo que destes, $29 \mathrm{~km}^{2}$ pertencentes do Rio das Pedras e $13 \mathrm{~km}^{2}$ ao Baixo Anhumas, tal área foi mensurada com o uso do software ArcGis 10 (Figura 1)

Ambas bacias apresentam forte índice de urbanização, com pequenos e médios fragmentos florestais localizados ao longo de sua área. Existe ainda, parte de dois remanescentes florestais, um em cada sub bacia, que são: a Mata do Quilombo na Sub Bacia do Baixo Anhumas e a Mata Santa Genebra na sub Bacia do Rio das Pedras. As áreas agrícolas estão espalhadas por toda a área de estudo, sendo essas de pequenos e médios produtores rurais, tendo características de manejo variáveis. Devido a maior área permeável e menor densidade populacional, a maior concentração de áreas agrícolas está inserida na Sub Bacia do Baixo Anhumas.

\section{Amostragem e analises dos dados}

Foi realizada uma análise de observação e caracterização ambiental de trechos de ambas as sub bacias em 37 pontos nas áreas permeáveis, sendo 9 localizados em áreas agrícolas, 11 em área urbana, e 17 em área vegetada (Tabela 1).

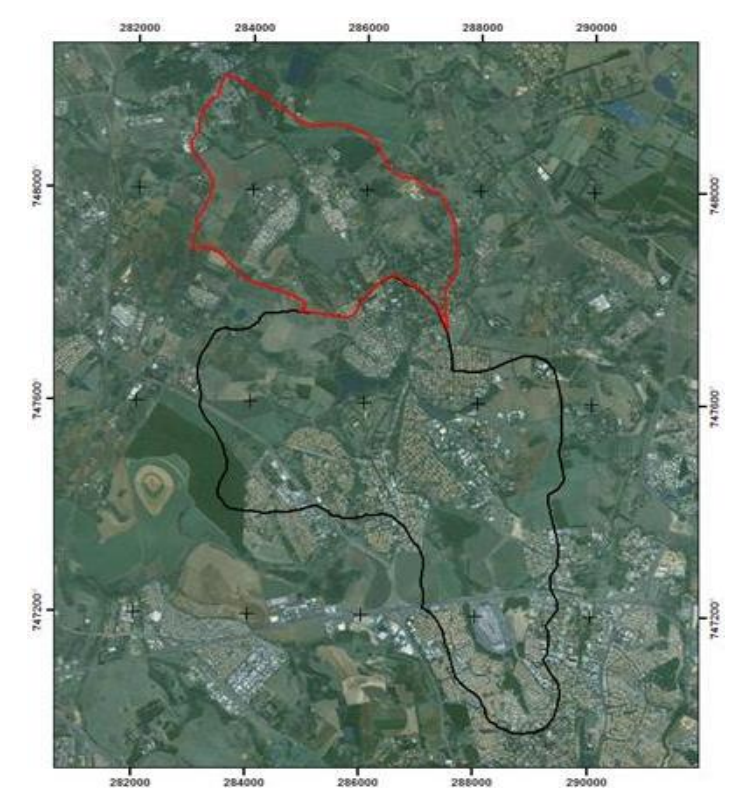

Figura 1. Localização das Sub Bacias do Baixo Anhumas (delimitação em vermelho) e Rio das Pedra (delimitação em preto), Campinas, São Paulo, Brasil.

Os pontos de amostragem foram definidos levando em consideração o distanciamento espacial para que não fossem extremamente próximos, nem demasiadamente longes a ponto de perder-se qualidade na diferenciação de algum elemento como tipo de solo, cobertura vegetal e ou uso. Tal distanciamento é possível ser analisado na Tabela 1.

Tabela 1. Coordenadas geográficas dos pontos amostrais (P) desta pesquisa e o tipo de uso e ocupação do solo.

\begin{tabular}{cccc||cccc}
\hline $\mathrm{P}$ & Long. & Lat. & Tipo & $\mathrm{P}$ & Long. & Lat. & Tipo \\
\hline 1 & 289199 & 7469919 & $\mathrm{U}$ & 20 & 287025 & 7476113 & $\mathrm{~V}$ \\
2 & 289161 & 7469877 & $\mathrm{U}$ & 21 & 286828 & 7476236 & $\mathrm{~V}$ \\
3 & 288878 & 7470455 & $\mathrm{~V}$ & 22 & 287042 & 7475982 & $\mathrm{~V}$ \\
4 & 288685 & 7470855 & $\mathrm{~V}$ & 23 & 287225 & 7474240 & $\mathrm{~V}$ \\
5 & 288562 & 7471128 & $\mathrm{~V}$ & 24 & 286838 & 7474335 & $\mathrm{~V}$ \\
6 & 288334 & 7471302 & $\mathrm{~V}$ & 25 & 285845 & 7480640 & $\mathrm{U}$ \\
7 & 287926 & 7471821 & $\mathrm{~V}$ & 26 & 286162 & 7480611 & $\mathrm{~A}$ \\
8 & 287819 & 7472226 & $\mathrm{~V}$ & 27 & 286162 & 7480673 & $\mathrm{U}$ \\
9 & 288794 & 7470556 & $\mathrm{U}$ & 28 & 286834 & 7480117 & $\mathrm{U}$ \\
10 & 288973 & 7471091 & $\mathrm{U}$ & 29 & 285980 & 7478996 & $\mathrm{U}$ \\
11 & 288896 & 7471271 & $\mathrm{U}$ & 30 & 285302 & 7479203 & $\mathrm{~A}$ \\
12 & 288936 & 7471328 & $\mathrm{~V}$ & 31 & 284691 & 7479171 & $\mathrm{~V}$ \\
13 & 288765 & 7471698 & $\mathrm{U}$ & 32 & 284720 & 7480264 & $\mathrm{~A}$ \\
14 & 288421 & 7472634 & $\mathrm{~A}$ & 33 & 285548 & 7477788 & $\mathrm{~A}$ \\
15 & 288383 & 7472927 & $\mathrm{~A}$ & 34 & 285520 & 7477769 & $\mathrm{~A}$ \\
16 & 289339 & 7473703 & $\mathrm{~A}$ & 35 & 285301 & 7478189 & $\mathrm{~V}$ \\
17 & 288787 & 7473478 & $\mathrm{~A}$ & 36 & 286855 & 7476822 & $\mathrm{~V}$ \\
18 & 288371 & 7475182 & $\mathrm{U}$ & 37 & 286867 & 7476467 & $\mathrm{~V}$ \\
19 & 287753 & 7475836 & $\mathrm{~V}$ & & & & \\
\hline
\end{tabular}

Legenda do tipo de uso e ocupação: Agrícola (A); Vegetado (V); Urbano (U).

Além da análise visual, realizou-se em todos os 37 
pontos, ensaio de resistência mecânica à penetração, com o auxílio de um penetrômetro de impacto tipo Stiboka e dois diferentes tipos de amostras de solo: amostras de solo indeformadas com volume conhecido, coletadas com anel volumétrico, com finalidade de determinar a densidade do solo (Kiehl, 1979), densidade de partículas (EMBRAPA, 1979) e a porosidade total (EMBRAPA, 1997) e; amostras de solo deformadas, coletadas com o auxílio de um trado e uma pá para análises de granulometria (Kiehl, 1979), fertilidade (IAC \& FUNDAG, 1997; Raij, Cantarella, Quaggio, \& Furlani, 2010), pH (EMBRAPA, 1997), umidade (EMBRAPA, 1979), cor, textura, metais pesados (EPA 3050B, e EPA 7000B) e matéria orgânica (método colorimétrico).

\section{Resultados e Discussão}

Por meio de estatística descritiva, foram apresentados o valor médio obtidos bem como o desvio padrão relacionados aos parâmetros de solo analisados nos 37 pontos ao longo das bacias hidrográficas estudadas dividindo e classificando de acordo com o uso e ocupação, tais valores podem ser vistos na Tabela 2 . De um modo geral, pode-se observar para alguns parâmetros o desvio padrão foi elevado, mesmo se tratando de um trabalho de campo, em função, provavelmente, da grande heterogeneidade de terrenos e de influências antrópicas observadas ao longo de toda a área.

Tabela 2. Comparação dos valores encontrados para os sobre atributos do solo com valores de referência de qualidade do solo.

\begin{tabular}{|c|c|c|c|c|}
\hline \multirow{2}{*}{ Atributo do solo } & \multicolumn{3}{|c|}{ Valor médio por tipo de área } & \multirow{2}{*}{$\begin{array}{l}\text { Valor de } \\
\text { referência }\end{array}$} \\
\hline & Vegetada & Agrícola & Urbana & \\
\hline RMP (Mpa) & $2,84 \pm 2,04$ & $3,07 \pm 0,94$ & $3,93 \pm 1,38$ & Até 2,5 \\
\hline M.O. $\left(\mathrm{g} / \mathrm{dm}^{3}\right)$ & $29,22 \pm 6,63$ & $31,33 \pm 12,89$ & $21,00 \pm 11,04$ & $31-60 *$ \\
\hline $\mathrm{pH}$ & $6,81 \pm 0,61$ & $6,30 \pm 0,52$ & $6,53 \pm 0,47$ & Até $4,3 *$ \\
\hline Areia $(\mathrm{g} / \mathrm{Kg})$ & $455,89 \pm 131$ & $368,78 \pm 136$ & $424,71 \pm 134$ & - \\
\hline Silte $(\mathrm{g} / \mathrm{Kg})$ & $103,89 \pm 69$ & $117,11 \pm 50$ & $163,14 \pm 113$ & - \\
\hline Argila (g/Kg) & $440,23 \pm 108$ & $514,11 \pm 67$ & $412,14 \pm 142$ & - \\
\hline $\mathrm{K}\left(\mathrm{mmol}_{\mathrm{c}} / \mathrm{dm}^{3}\right)$ & $4,45 \pm 2,19$ & $4,68 \pm 2,55$ & $3,42 \pm 1,84$ & $1,6-3,0^{*}$ \\
\hline $\mathrm{P}\left(\mathrm{mmol} / \mathrm{dm}^{3}\right)$ & $36,67 \pm 36$ & $63,33 \pm 69$ & $10,71 \pm 10,7$ & \\
\hline $\mathrm{Ca}\left(\mathrm{mmol}_{\mathrm{c}} / \mathrm{dm}^{3}\right)$ & $77,56 \pm 31$ & $56,00 \pm 38$ & $33,14 \pm 22$ & $>7,00 *$ \\
\hline $\operatorname{Mg}\left(\mathrm{mmol}_{\mathrm{c}} / \mathrm{dm}^{3}\right)$ & $17,33 \pm 4,74$ & $14,67 \pm 6,7$ & $9,71 \pm 4,7$ & $5,0-8,0^{*}$ \\
\hline Soma de Base $\left(\mathrm{cmol}_{\mathrm{c}} / \mathrm{dm}^{3}\right)$ & $99,22 \pm 35$ & $75,55 \pm 46$ & $46,42 \pm 28$ & $1,81-3,60 * *$ \\
\hline $\mathrm{CTC}\left(\mathrm{cmol}_{\mathrm{C}} / \mathrm{dm}^{3}\right) * 1$ & $122,88 \pm 30$ & $107,89 \pm 39$ & $73,71 \pm 30$ & $>8,0 * *$ \\
\hline $\mathrm{V}(\%) * 2$ & $77,8 \pm 16$ & $63,11 \pm 21$ & $58,57 \pm 19$ & $26-50 * *$ \\
\hline $\mathrm{S}\left(\mathrm{mmol}_{\mathrm{c}} / \mathrm{dm}^{3}\right)$ & $9,11 \pm 1,8$ & $9,89 \pm 2,7$ & $8,86 \pm 1,35$ & $>7,5^{*}$ \\
\hline $\mathrm{B}\left(\mathrm{mmol}_{\mathrm{c}} / \mathrm{dm}^{3}\right)$ & $0,18 \pm 0,03$ & $0,16 \pm 0,02$ & $0,12 \pm 0,05$ & $0,21-0,60^{* *}$ \\
\hline $\mathrm{Cu}\left(\mathrm{mmol}_{\mathrm{c}} / \mathrm{dm}^{3}\right)$ & $3,62 \pm 2,7$ & $7,33 \pm 3,4$ & $3,54 \pm 4$ & $0,8-1,2^{* *}$ \\
\hline $\mathrm{Fe}\left(\mathrm{mmol}_{\mathrm{c}} / \mathrm{dm}^{3}\right)$ & $8,44 \pm 13$ & $12,67 \pm 11$ & $10,57 \pm 8$ & $>45 * *$ \\
\hline $\operatorname{Mn}\left(\mathrm{mmol}_{\mathrm{c}} / \mathrm{dm}^{3}\right)$ & $18,91 \pm 21$ & $38,6 \pm 31$ & $15,91 \pm 17$ & $>12 * *$ \\
\hline $\mathrm{Zn}\left(\mathrm{mmol}_{\mathrm{c}} / \mathrm{dm}^{3}\right)$ & $2,44 \pm 1,9$ & $2,77 \pm 2,2$ & $2,02 \pm 1,8$ & $>2,2 * *$ \\
\hline Densidade do solo $\left(\mathrm{g} / \mathrm{cm}^{-3}\right)$ & $1,34 \pm 0,23$ & $1,47 \pm 0,21$ & $1,57 \pm 0,17$ & $1,0-1,25$ \\
\hline Densidade das partículas $\left(\mathrm{g} / \mathrm{cm}^{-3}\right)$ & $2,76 \pm 0,22$ & $3,00 \pm 0,40$ & $2,95 \pm 0,16$ & $2,3-2,9 *$ \\
\hline Porosidade Total (\%) & $0,51 \pm 0,09$ & $0,50 \pm 0,09$ & $0,47 \pm 0,07$ & $52,8-61,5^{*}$ \\
\hline Umidade $(\%)$ & $23,61 \pm 4,5$ & $26,74 \pm 4,6$ & $23,64 \pm 5,5$ & - \\
\hline
\end{tabular}

Pode-se observar ainda, que para o caso das análises de resistência mecânica a penetração, as áreas vegetadas tiveram maior variabilidade de valores, resultando em um desvio padrão maior que as demais áreas. Acredita-se que isso se deve diretamente a intervenção humana (mais intensa ou sutil) nas diferentes áreas das bacias. Quando ao índice de matéria orgânica, ainda analisando a Tabela 1, pode-se inferir que em todas os usos tiveram-se valores variáveis para o nutriente, indicando o manejo e manutenção das áreas. No caso especifico de áreas agrícolas, em alguns pontos pode ser observado início do processo de plantio, o que infere em uma adubação em um curto período de tempo, o que pode explicar a diferença de valores.

Considera-se ainda que com base nos desvios e nas medias apresentadas, que as áreas urbanas e as vegetadas vem apresentando maior fragilidade ambiental, do que as áreas agrícolas, isso deve-se mais uma vez, ao correto manejo da área. A importância de um manejo correto para plantio agrícola, interfere diretamente na qualidade produtiva da área, fazendo com que o produtor leve em consideração todos os índices de qualidade do solo, trabalhando para adequá-los.

A Mata do Quilombo e as observações levantadas no interior dela, são apresentadas na Figura 2A, estando este trecho de mata nativa, localizado na sub bacia do Baixo Anhumas, representado nessa pesquisa pelo ponto P25. Trata-se do fragmento florestal de maior representatividade na bacia, o qual mesmo sendo preservada por lei, vem sofrendo diversas pressões antrópicas. Na Figura 2B, ponto $\mathrm{P} 27$, pode-se observar um trecho da mata, próximo à 
estrada que liga ao bairro e a área de pastagem, verificando-se diversas árvores queimadas. Pela disponibilidade da matéria orgânica do solo e por relatos de moradores do entorno, foi possível visualizar que o local sofre por frequentes episódios de queimadas. Ainda, em todo trecho de mata ciliar do rio (Figura 2C) foi possível identificar descarte de resíduos da construção civil, lixo doméstico, plantas invasoras, cultos religiosos e trafego de pessoas, o que pode promover uma compactação e contaminação do solo e da água, levando a uma fragilização do ecossistema.

Para Tamanini, 2008, o conceito de fragilidade ambiental refere-se ao dano sofrido ao meio ambiente frente a fatores de desequilíbrio de ordem natural ou antrópica, sendo a natural por meio de processos erosivos e pela própria dinâmica ambiental, enquanto as antrópicas podem, por exemplo, ser ocasionada pelo mau uso do solo e pelas intervenções nos regimes fluviais. Damame, Longo, Ribeiro, \& Fengler, 2015 observaram impactos diretos das ações antrópicas que comprometem a qualidade ambiental dos ambientes estudados nestas bacias hidrográficas.

Foi possível observar a proximidade das residências com as margens do rio das Pedras (Figura 2D), o que poderá influenciar na compactação e na infiltração e percolação de água no solo.

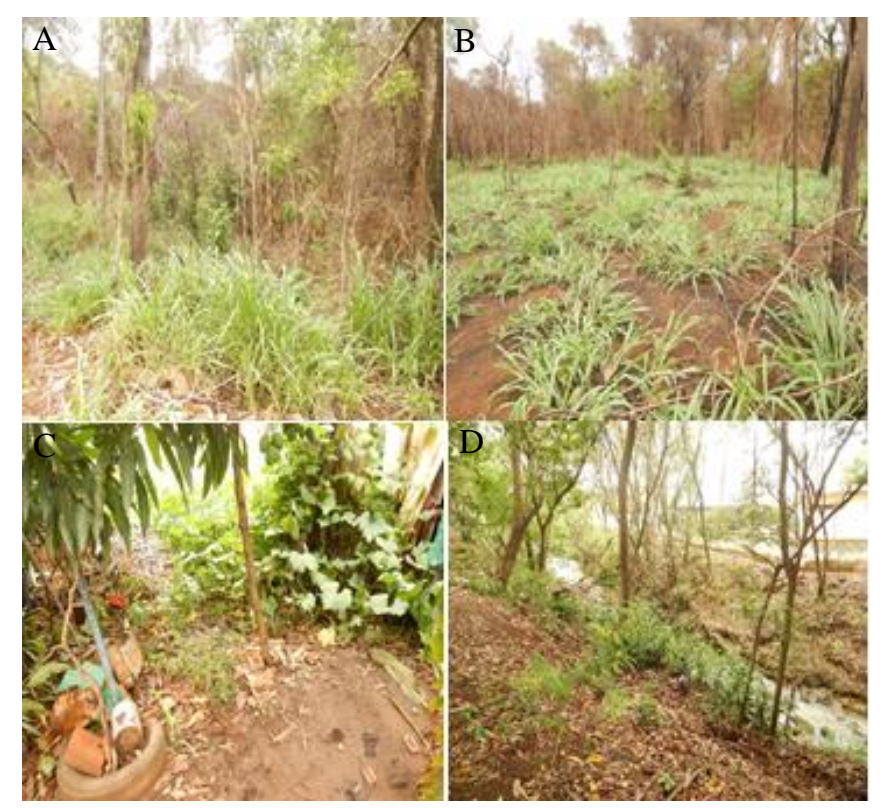

Figura 2. Trecho interno da mata do quilombo (A). Trecho de borda da mata do Quilombo, próximo a estrada e pastagem (B). Trecho da mata ciliar do Rio das Pedras (C). Trecho de mata ciliar do Rio das Pedras, proximidade das residências com a calha do rio e APP (D).

Na Figura 3A observa-se uma área densamente urbanizada, com um grande shopping Center, cercado por grande urbanização, apresentando características de análise de solo deficientes em termos químicos, e elevados padrões físicos, o que certamente poderá conduzir a uma deficiência nutricional, além de promover a compactação deste solo. A principal rodovia que cerca o shopping, a Rodovia Dom Pedro, possui 145,5 Km de extensão e interligando diversas cidades do interior paulista, tendo um fluxo extremamente intenso de veículos.

$\mathrm{Na}$ região nordeste da Sub Bacia do Baixo Anhumas, encontrou-se uma área de descarte de resíduo de construção 4 civil, (Figura 3B, representada pelo ponto P28). Estes resíduos são utilizados para terraplanagem de diversas áreas, além disso, a região caracteriza-se por um solo com alto teor de areia. Neste local, existe um déficit nos valores dos atributos analisados, principalmente nos relacionados a fertilidade, e ainda, o $\mathrm{pH}$ apresentou os menores valores encontrados na área de estudo. Os atributos físicos também sofreram impactos relacionados à compactação, possivelmente, esse fator atribui-se ao trânsito de veículos pesados na área. Segundo Vasconcelos, Souza, Cantalice, \& Silva, 2014, os sistemas de manejo do solo provocaram alterações em seus atributos físicos, aumentando a densidade e o grau de compactação e reduzindo a condutividade hidráulica saturada quando comparados com a mata nativa.

No início da Sub Bacia do Rio das Pedras, na parte mais alta da área de estudo, tem-se um pequeno trecho urbano com alto déficit nutricional, tal ponto caracteriza-se em uma área de Nitossolo, altamente urbanizada, em meio a postos de gasolina, grandes avenidas e loteamentos residenciais (Figura 3C, ponto P01). A falta de nutrientes no solo pode estar associada ao tipo de solo que constitui o trecho, a declividade (que facilita perda de matéria orgânica) e ainda a processos de urbanização. Segundo Ralisch et al., 2008, a compactação de um solo pode produzir efeitos diretos nas propriedades físicas, a resistência mecânica, por exemplo, aumenta em função da compactação, enquanto a porosidade total decresce, o que pode ser observado na área estudada.

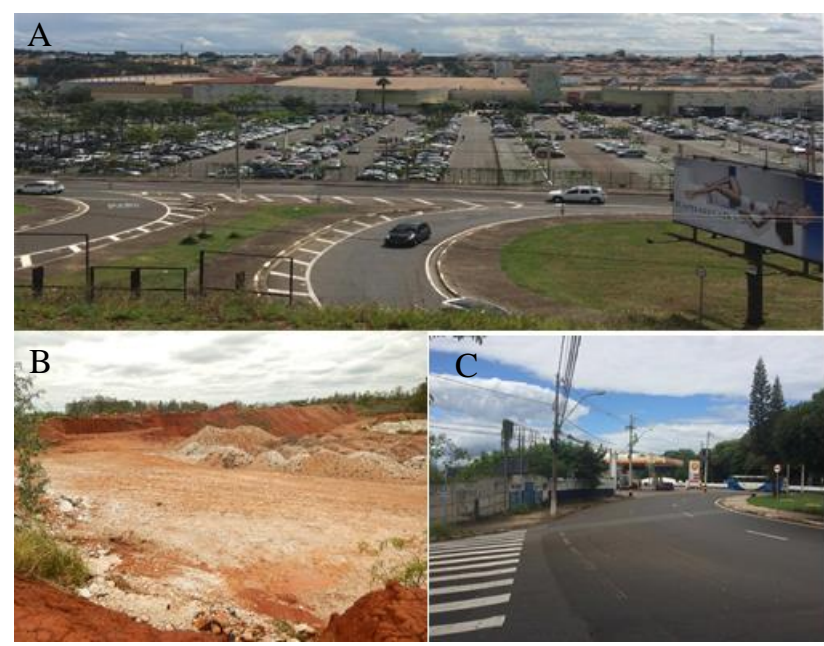

Figura 3. Parque Dom Pedro Shopping e seu entorno cercado por rodovias, avenidas e residências (A). Área de destarte de resíduos de construção civil (B). Trecho mais alto da Bacia do Rio das Pedras, ponto inicial, antes da nascente do rio $(\mathrm{C})$.

$\mathrm{Na}$ área estudada localiza-se três tipos de cenários rurais, o primeiro constituído de pastagens e áreas agrícolas medianas (Figura 4A), ponto P26), os quais apresentaramse cercados por condomínios, residências e estradas, e vem sofrendo constantemente pressão imobiliária. Outro cenário comum na bacia são as áreas agrícolas abandonadas (Figura 4B), ponto P15) que já estão perdendo espaço para a urbanização, onde em um futuro breve será utilizado para construção de loteamentos, uma vez que a área foi 
adquirida por uma grande construtora, a qual já está solicitando licenças para início das obras. O terceiro cenário foram as áreas de chácaras para produção de hortaliças, normalmente agricultura familiar, com poucas pessoas trabalhando e sem grandes maquinas, o cultivo principal nessas áreas são as frutas e hortaliças (Figura 4C, Ponto P35).

Na parte média das Sub Bacias foi o local onde observou o surgimento de novos loteamentos, sendo caracterizada como a área de maior tendência a expansão imobiliária, sendo este o local que atualmente é ocupado pela maior parte da parcela agrícola, a qual poderá ser substituída por condomínios. Segundo Miller, (2007) quando as grandes cidades se expandem, acabam prejudicando o solo para cultivos rurais, florestas, áreas úmidas e habitats de animais selvagens, o que torna inviável a utilização das demais áreas para fornecimento de alimento, água, energia mineral e etc., pois tais atividades diminuem e destroem a biodiversidade local.
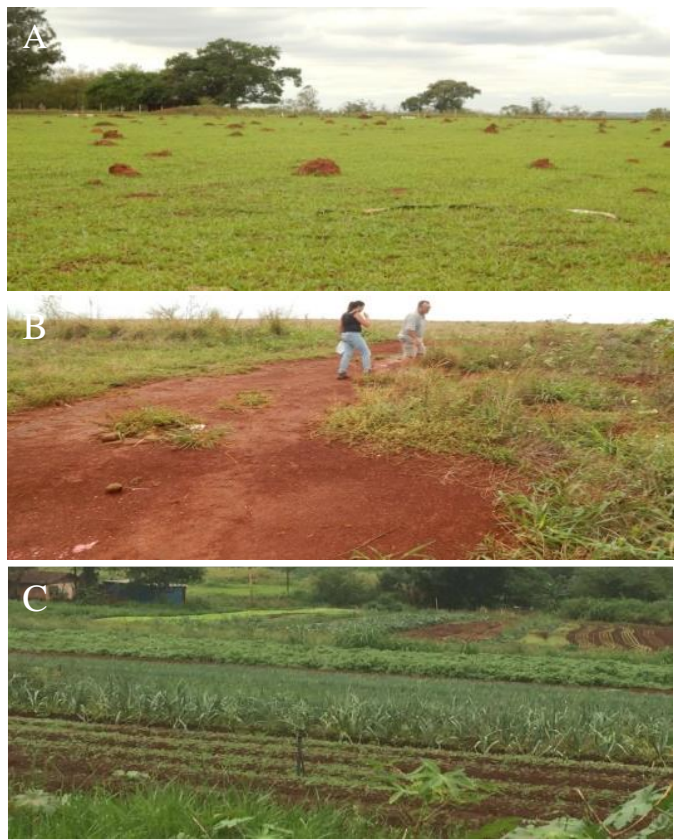

Figura 4. Trecho agrícola (A). Extensa área agrícola abandonada na Sub Bacia do Rio das Pedras (B). Pequena horta de agricultura familiar encontrada na Sub Bacia do Baixo Anhumas (C).

O Existem ainda, trechos urbanos e rurais preservados no decorrer da Bacia, o primeiro deles é a nascente principal do rio das Pedras, ponto P04 neste foi possível identificar uma importante área de mata, que acompanha o rio por cerca de 50 metros, formando um pequeno bosque Ponto P03 e P02 (Figuras $5 \mathrm{~A}$ e $5 \mathrm{~B})$. Seu entorno é cercado por ruas e casas, mas ainda sim constitui um importante trecho de mata preservada na bacia. Neste trecho observou-se os maiores índices de fertilidade do solo e ainda o maior $\mathrm{pH}$, podendo os resultados estar relacionado ao acumulo de matéria orgânica na área, uma vez que a nascente mesmo degradada, conta com a proteção do pequeno bosque.

Outro trecho a ser observado é um pequeno remanescente próximo ao shopping Dom Pedro, no ponto P12 (Figura 5C) localizado atualmente no interior de um condomínio de alto padrão. O mesmo foi cercado totalmente com tela, e portões, sua entrada é extremamente restrita, sendo liberada para as análises deste trabalho apenas com autorização previa dos condôminos. Neste local, pode-se observar um elevado teor de matéria orgânica, além de alta CTC, Soma de bases e V\%, indicando uma boa fertilidade na área, podendo está a ser atribuída a conservação do horizonte $\mathrm{O}$ na região.

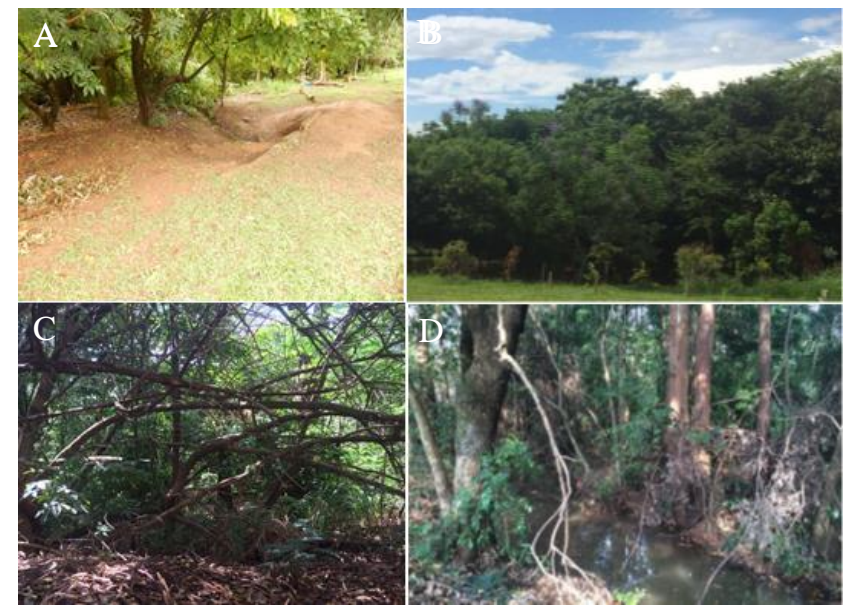

Figura 5. Nascente principal do Rio das Pedras (A). Pequeno bosque formado ao redor na nascente principal do Rio das Pedras (B). Pequeno trecho de mata entre os condomínios de alto padrão ao redor do shopping Dom Pedro (C). Pequena área de mata nativa entre áreas rurais e condomínios na Sub Bacia do Baixo Anhumas (D).

Em uma parcela entre área rural e condomínios residenciais, na Sub Bacia do Baixo Anhumas, pode-se observar a existência de uma pequena área de mata nativa e um pequeno curso d'água (Figura 5D, Ponto P32), sendo este o ponto que se apresentou com valores mais elevados de fertilidade e de $\mathrm{pH}$ entre 6,5 a 7,0, apresentando-se adequado para o cultivo. A análise de uma situação como essa corrobora para a discussão sobre a importância da manutenção das áreas nativa para manutenção da qualidade dos solos, onde, realizar esta manutenção torna-se primordial para a sustentabilidade das áreas (Mercante, Fabricio, Machado, \& Silva, 2004). Manter a vegetação nativa é essencial para a ciclagem de água e de matéria, além de regular a temperatura e prover maior aproveitamento da biodiversidade local (Ferreira, Campos, Creado, Mendes, \& Caropreso, 2007). Quando se maneja inadequadamente ou intensivamente um solo, ocasiona-se um estado de degradação que irá requerer tempo e recursos para que seja possível sua recuperação, fazendo-se necessário o monitoramento das áreas por um longo período afim de assegurar sua qualidade (Mendes, Reis Júnior, \& Perreira Neto, 2002).

De modo geral, as Sub Bacias analisadas nesse estudo, vem sofrendo ao longo dos anos processos de fragilização de seus ecossistemas, como pôde ser constatado por meio dos resultados das análises de solo, em um comparativo com as principais áreas vulneráveis na bacia. A ocupação urbana foi responsável direta pelas alterações sofridas na área, principalmente ao longo do período estudado, podendo ser constatado pela observação do aumento dos níveis de vulnerabilidade justamente nas áreas onde 
ocorreu o maior desenvolvimento da mancha urbana. Aliado a isso, a constante perda de área agrícola, também traz prejuízos ambientais, uma vez que como pode ser visualizado por esse e outros estudos, que áreas agrícolas auxiliam nos processos ambientais, como qualidade do solo, infiltração de água, aeração, ocupação de organismos vivos e etc, enquanto a área urbana, aliado a impermeabilização do solo, impede que quaisquer dos citados acima ocorram.

Neste contexto, (Etto, Longo, Arruda, \& Invenioni, 2014) afirmam que as áreas com cobertura vegetal, apresentaram de forma geral, uma qualidade ambiental prejudicada pela ação antrópica do entorno, principalmente devido a crescente pressão imobiliária. Contudo, em bacias urbanas quando as pressões antrópicas são minimizadas as áreas possuem condições mínimas necessárias para o restabelecimento da cobertura vegetal (Fengler et al., 2015).

\section{Conclusões}

No cenário atual dos impactos antrópicos do solo em ambas as bacias, percebe-se que a ocupação urbana foi responsável direta pelas alterações sofridas na área, pois, além de impermeabilizar o solo, afeta diretamente a interação entre os fragmentos florestais, impedindo a ciclagem de nutrientes, correta percolação de água, manutenção do banco de sementes entre outros.

A análise dos atributos físico e químicos do solo reportou que grande parte destes demonstraram a fragilização do ecossistema, estando abaixo dos índices consideráveis adequados para o desenvolvimento e estabelecimento das culturas, sejam agrícolas ou arbóreas, sendo nativas ou não.

\section{Referências}

Companhia de tecnologia em saneamento ambiental do estado de São Paulo CETESB. (2005). Decisão de Diretoria no ${ }^{195-2005 . ~ S a ̃ o ~ P a u l o: ~ C E T E S B . ~}$ Recuperado https://www.ministeriodesalud.go.cr/gestores_en_salud/pozoAB1089/tabela_valores_2005.pdf

Companhia de tecnologia em saneamento ambiental do estado de São Paulo. (2014). Decisão de diretoria $n^{\circ}$ 045/2014 para valores orientadores para solos e águas subterrâneas no Estado de São Paulo. São Paulo: CETESB. Recuperado de https://cetesb.sp.gov.br/solo/wpcontent/uploads/sites/18/2014/12/DD-045-2014-P53.pdf

Coelho, R. M., Torres, R. B. \& Berenacci, L. C. (2007). Solos e Vegetação Nativa Remanescente no Município de Campinas, Pesquisa Agropecuária Brasileira, 42(9), 1319-1327. doi: 10.1590/S0100-204X2007000900014

Damame, D., Longo, R., Ribeiro, A. \& Fengler, F. (2015). Variation of the anthropic vulnerability in Ribeirão das Pedras watershed in Campinas/SPBrazil (vol. 17), Anais do General Assembly Conference Abstracts. Vienna, Austria. Recuperado de http://adsabs.harvard.edu/abs/2015EGUGA..17..577D

Empresa Brasileira de Pesquisa Agropecuária. (1997). Manual de métodos de análise de solo. 2: revisão atual. Serviço Nacional de Levantamento e Conservação de Solos. Rio de Janeiro, Rio Janeiro, Brasil. Recuperado de https://www.agencia.cnptia.embrapa.br/Repositorio/Manual+de+Metodos_ 000fzvhotqk02wx5ok0q43a0ram31wtr.pdf

Empresa Brasileira de Pesquisa Agropecuária. (1979). Manual de métodos de análise de solo. Serviço Nacional de Levantamento e Conservação de Solos, Rio de Janeiro, Brasil.

Environmental Protection Agency. (1996). Acid Digestion of Sediments, Sludges, and Soils. Método 3050B-SW 846.

Environmental Protection Agency. (2007). Flame Atomic Absorption Spectrophotometry. MÉTODO 7000B-SW 846.

Environmental Systems Research Institute. (2014). ArcGis 10.1 ESRI Inc.
Etto, T. L., Longo, R. M., Arruda, D. D. R. \& Invenioni, R. (2013). Ecologia da paisagem de remanescentes florestais na Bacia Hidrográfica do Ribeirão das Pedras-Campinas-SP, Revista Árvore, 37(6), 1063-1071. doi: 10.1590/S0100-67622013000600007

Fengler, F. H., Moraes, J. F., Ribeiro, A. I., Peche, A., Storino, M. \& Medeiros, G. A. D. (2015). Qualidade ambiental dos fragmentos florestais na Bacia Hidrográfica do Rio Jundiaí-Mirim entre 1972 e 2013, Revista Brasileira de Engenharia Agrícola e Ambiental, 19(4), 402-408. doi: 10.1590/1807-1929/agriambi.v19n4p402-408

Food and Agriculture Organization of the United Nations. (1995). Forest Resources Assessment 1990: Global Synthesis. Rome: FAO Forestry, Paper.

Freire, F. M. (2006). Cultivo do milho: Fertilidade de solos. Sete Lagoas: Embrapa Milho e Sorgo.

Instituto Agronômico. Interpretação de Resultados de Análise de Solo. Campinas: Instituto Agronômico, Centro de Pesquisa e Desenvolvimento de Solos e Recursos Ambientais.

Instituto Agronômico de Campinas, Fundação de Apoio à Pesquisa Agrícola. (1997). Interpretação de resultados de análise de solo. Boletim técnico, 100, 8-13.

Kiehl, E. J. (1970). Manual de edafologia: relações solo-planta. São Paulo: Ceres.

Leitão, F. H. F. (2000). Matas Ciliares: Conservação e Recuperação. São Paulo: Editora da Universidade de São Paulo. pp. 33-44.

Lima, P. W. \& Zakia, B. M. J. (2000). Hidrologia de matas ciliares. Matas Ciliares: Conservação e Recuperação. São Paulo: Edusp. pp. 33-44. Recuperado de http://www.ipef.br/hidrologia/mataciliar.asp

Medeiros, R. B.., Pinto, A. L., São Miguel, A. E. 7 Oliveira, G. H. (2014). Avaliação da vulnerabilidade ambiental na área do assentamento São Joaquim, Selvíria. Caminhos de Geografia, 15(49), 126-137.

Mendes, I. C., Reis Jr., F. \& Perreira Neto, J. V. (2002, abril). Uso de indicadores biológicos e bioquímicos para avaliar a qualidade de solos de cerrado sob plantio direto e convencional (p. 54). Anais da $26^{a}$ Reunião Brasileira de Fertilidade do Solo e Nutrição de Plantas, $9^{\mathrm{a}}$ Reunião Brasileira sobre Micorrizas, $7^{\circ}$ Simpósio Brasileiro de Microbiologia do Solo, $4^{\mathrm{a}}$ Reunião Brasileira de Biologia do Solo. Petrolina, Pernambuco, Brasil.

Mercante, F. M., Fabricio, A. C., Machado, L. A. Z. \& Silva, W. M. (2004). Parâmetros microbiológicos como indicadores da qualidade do solo sob sistemas integrados de produção agropecuária. Recuperado https://www.infoteca.cnptia.embrapa.br/handle/doc/252733

Miller Jr., G. T. (2007). Ciência ambiental. São Paulo: Thomson Learning.

Moura, S. R. F., Grigio, A. M. \& Diodato, M. A. (2010). Mapeamento e Análise da Vulnerabilidade Natural e Ambiental do Município de Mossoró. Seminário Nacional de Governança Urbana e Desenvolvimento Metropolitano, Natal, Rio Grande do Norte.

Oliveira, F. F. G. \& Mattos, J. T. (2014). Análise ambiental de remanescentes do bioma Mata Atlântica no litoral sul do Rio Grande do Norte - NE do Brasil. GEOUSP - Espaço e Tempo, 18(1), 165183. doi: 10.11606/issn.2179-0892.geousp.2014.81095

Raij, B. V., Cantarella, H., QUAGGIO, J. A. \& FURLANI, A. M. C. (1997). Recomendações de adubação e calagem para o estado de São Paulo. Boletim Técnico - Instituto Agronômico de Campinas, 2, 285.

Ralisch, R., Miranda, T. M., Okumura, R. S., Barbosa, G. M. D. C., Guimarães, M. D. F., Scopel, E. \& Balbino, L. C. (2008). Resistência à Penetração de um latossolo vermelho amarelo do cerrado sob diferentes sistemas de manejo, Revista Brasileira de Engenharia Agrícola e Ambiental, 12(4), 381-384.

Rambaldi, D. M. \& Oliveira, D. (2003). Fragmentação de ecossistemas: causas, efeitos sobre a biodiversidade e recomendações de políticas públicas (Vol. 6, pp. 66-99). Brasília: Secretaria de Biodiversidade e Florestas, Ministério do Meio Ambiente.

Rodrigues, R. R. \& Freitas, L. F. H. (2000). Matas ciliares: conservação e recuperação (pp. 33-44). São Paulo: Edusp.

Tamanini, M. S. A. (2008), Diagnóstico Físico-Ambiental para determinação da fragilidade potencial e emergente da Bacia do Baixo Curso do Rio Passaúna em Araucária - PR (Dissertação de Mestrado). Universidade Federal do Paraná, Curitiba, Paraná, Brasil. Recuperado de https://acervodigital.ufpr.br/handle/1884/15140 
Tambosi, L. R. (2014). Estratégias espaciais baseadas em ecologia de paisagens para a otimização dos esforços de restauração (Tese de doutorado). Universidade de São Paulo. São Paulo, Brasil. Recuperado de http://www.teses.usp.br/teses/disponiveis/41/41134/tde-29052014112453/en.php

Vasconcelos, R. F., Souza, E. R., Cantalice, J. R. \& Silva, L. S. (2014). Qualidade física de Latossolo Amarelo de Tabuleiros Costeiros em Diferentes Sistemas de Manejo da Cana-de-Açúcar. Revista Brasileira de Engenharia Agrícola e Ambiental, 18(4), 381-386. doi: 10.1590/S141543662014000400004

\section{Licença Creative Commons CC BY 4.0}

Este artigo foi publicado com acesso aberto para distribuíção sob os termos do Licença de Atribuição Creative Commons, que permite uso irrestrito, distribuição, e reprodução em qualquer meio, desde que o trabalho original seja devidamente citado. 